Азиатско-Тихоокеанский регион: экономика, политика, право. 2021. Т. 24, № 4. С. 99-110. Pacific Rim: Economics, Politics, Law. 2021. V. 24, No 4. P. 99-110.

\title{
ПОЛИТИКА
}

Научная статья

УДК 327(510:98)

https://doi.org/10.24866/1813-3274/2021-4/99-110

\section{ПОЗИЦИОНИРОВАНИЕ КИТАЯ В АРКТИКЕ: ЭВОЛЮЦИЯ КОНЦЕПЦИЙ И МЕХАНИЗМЫ ПРОДВИЖЕНИЯ}

\author{
Лэй Шуан ${ }^{1,2}$ \\ ${ }^{1}$ Хайнаньский университет, КНР, пров. Хайнань, Хайкоу, Жэньминь-Авеню, \\ № 58; leishuang@yandex.com \\ 2 Дальневосточный федеральный университет, 690922, Россия, Приморский \\ край, г. Владивосток, о. Русский, п. Аякс, 10
}

Аннотация. Китайское руководство придерживается позиции интернализации Арктики и расширения прав участия неарктических государств в её освоении. Не имея прямых формально-юридических инструментов воздействия на арктическую повестку, Китай действует с помощью активного лоббирования своих интересов в Арктическом совете, заключения двухсторонних договоров с арктическими странами, а также конструирования специфических концепций, обосновывающих его легитимность в арктическом регионе. Первой из них стала концепция «приарктической страны», предложенная Китаем в 2010 г. Позднее было признано, что статус «приарктического государства» недостаточен для расширяющегося китайского присутствия в Арктике, и была выдвинута новая концепция позиционирования Китая как «заинтересованной стороны в Арктике» (Arctic Stakeholders), которая опирается на более чёткую юридическую определённость. Согласно этой концепции, страны (и группы лиц) с соответствующими интересами, независимо от того, где они расположены, имеют право участвовать в обсуждении вопросов и решений, которые могут их затронуть. Именно самоидентификация в качестве «арктической заинтересованной стороны» позволяет Китаю наиболее последовательно артикулировать свои интересы, налаживать политическую коммуникацию с заинтересованными группами, влиять на принятие решений в институтах управления Арктикой.

(C) Лэй Шуан, 2021 
Смена арктических концепций отражает попытки Китая преодолеть навязанную ему дискриминирующую идентичность «неарктической страны» и сконструировать такой арктический дискурс, который позволял бы ему расширять свои права и повышать международный статус. При этом КНР всегда позиционирует себя как сторонник мирного взаимовыгодного сотрудничества («win-win result») в Арктике.

Ключевые слова: Китай, Арктика, неарктическое государство, приарктическая страна, заинтересованная сторона в Арктике, арктическая политика, позиционирование, арктическая идентичность, Арктический совет, арктическое управление.

Для циттирования: Лэй Шуан. Позиционирование Китая в Арктике: эволюция концепций и механизмы продвижения // Азиатско-Тихоокеанский регион: экономика, политика, право. 2021. Т. 24, № 4. С. 99-110. https://doi.org/10.24866/18133274/2021-4/99-110.

\title{
POLITICS
}

Original article

\section{CHINA'S POSITIONING IN THE ARCTIC: EVOLUTION OF CONCEPTS AND PROMOTION MECHANISMS}

\author{
Lei Shuang ${ }^{1,2}$ \\ ${ }^{1}$ Hainan University, China, Hainan Province, Haikou, № 58, Renmin Avenue; \\ leishuang@yandex.com \\ ${ }^{2}$ Academic Researcher of Far Eastern Federal University, 690922, Russia, \\ Vladivostok, Russkiy Island, 10 Ajax Bay
}

Abstract. The Chinese government adheres to the position of internalizing the Arctic and expanding the non-Arctic States rights. Lacking formal legal instruments to influence the Arctic agenda, China acts by actively lobbying its interests in the Arctic Council, concluding bilateral agreements with Arctic countries, as well as constructing specific concepts that justify its legitimacy in the Arctic region: in 2010, China proposed the concept of a «Near-Arctic State». Later, it was recognized that the status of «Arctic State» was insufficient to expand the Chinese presence in the Arctic, and a new concept of positioning China as one of the «Arctic Stakeholders» was put forward, which has a clearer legal definition. According to this concept, states (and groups of people) with relevant interests, regardless of their location, have the right to participate in the discussion of issues and decisions that may affect them. It is the self-identification as an «Arctic stakeholder» that allows China to most consistently articulate its interests, establish political 
communication with interested groups, and influence decision-making in the institutions of Arctic governance. The change in Arctic concepts reflects China's struggle with the discriminatory identity as a «Non-Arctic State» imposed on it and the construction of an Arctic discourse that would allow it to expand its rights and raise its international status. At the same time, China has always positioned itself as a supporter of peaceful, mutually beneficial cooperation («win-win result») in the Arctic.

Key words: China, Arctic, Non-Arctic State, Near-Arctic State, Arctic Stakeholder, Arctic affairs, positioning, arctic identity, Arctic Council, Arctic governance.

For citing: Lei Shuang. China's positioning in the Arctic: evolution of concepts and promotion mechanisms // Pacific Rim: Economics, Politics, Law. 2021. V. 24, No. 4. P. 99-110. https://doi.org/10.24866/1813-3274/2021-4/99-110.

В последние годы Китай превратился в одного из наиболее активных участников расширяющегося процесса освоения Арктики. Цели арктической политики Китая определяются потребностями его внутреннего развития и местом в глобальной экономической и политической системе. Экономика КНР, которая стала «фабрикой мира» и крупнейшей морской торговой державой, нуждается в природных ресурсах и логистических коридорах, которые может предложить Арктика. Китайское политическое руководство, которому удалось в последние 40 лет осуществить успешный модернизационный проект (ВВП Китая стабильно растет на 6-12\% в год) стремится к расширению международного влияния и повышению статуса КНР. Интерес к институтам управления Арктикой соответствует росту экономического и политического влияния КНР в глобальном масштабе. Кроме того, зрелые политические системы, к которым относится и Китай, стремятся к экстенсивному экономическому росту, а их элиты - к увеличению ренты. Арктика предоставляет китайским элитам доступ как к природной (минеральные, энергетические и логистические ресурсы), так и символической ренте (положительный имидж, научный престиж, демонстрационный эффект для китайских высоких технологий, информационные поводы для первых лиц государства). Важное значение в этом контексте приобретает анализ содержания, эволюции и механизмов продвижения концепций, с помощью которых Китай артикулирует свои интересы и расширяет легитимность своего присутствия в Арктике, добивается повышения международного статуса и доступа к принятию решений в институтах арктического управления в конце XX - начале XXI вв.

Отдельные аспекты формирования и позиционирования арктической идентичности Китая анализировались в работах российских [2] и китайских учёных [12]. Данная статья содержит анализ преимущественно китайских источников. В методологическом плане она опирается на структурно-функциональный подход, предложенный Г. Алмондом [1], с заимствованием таких единиц анализа, как «артикуляция интересов», «агрегирование заинтересованных групп», «кооптация в структуры 
принятия решений». В ней также использованы некоторые идеи теории идентичности, такие как «легитимирующая (навязанная) идентичность», «идентичность сопротивления» и «проективная идентичность» [4].

\section{Борьба Китая против дискриминирующей идентичности в Арктике}

Эволюция концепций позиционирования Китая в Арктике отражает указанные выше тенденции роста его экономического и политического влияния. Статус «неарктического государства», который получил Китай в начальный период его участия в арктических делах, представляет собой типичный пример «легитимирующей идентичности», которая вводится господствующими политическими акторами для расширения и рационализации своего господства над иными участниками социального взаимодействия [2]. Как способ идентичности «неарктические государства» соотносятся с «арктическими государствами» по принципу бинарной оппозиции, как бесправные/полноправные участники взаимодействия в арктическом регионе. Эта идентичность была сформулирована в «Оттавской декларации», принятой в 1996 году, когда был учреждён Арктический совет. Восемь стран - Дания, Исландия, Норвегия, Швеция, Финляндия, Россия, США и Канада - называются «арктическими» в зависимости от географических границ, а страны, отличные от восьми арктических стран, именуются «неарктическими государствами» (государствами, расположенными за пределами арктического региона) [3]. Возникло явное различие между узким привилегированным клубом «арктических стран» (А-8) и всеми остальными «неарктическими странами», что привело к дискриминации и даже исключению стран за пределами региона из участия в арктических делах. Это стало важным фактором, препятствующим сотрудничеству между Китаем и странами внутри и за пределами региона и началом долгой борьбы КНР (и других «неарктических государств») за расширение своих прав в Арктике [15, с. 125].

Китайское руководство придерживается позиции расширения прав неарктических государств на деятельность в Арктике. Аргументы, на которые оно при этом опирается, заключаются в том, что многие проблемы Арктического региона (изменение климата, загрязнение акватории и побережья приполярных морей, проблемы рыболовства, устойчивое развитие Арктики и т.д.) имеют глобальные последствия и требуют сотрудничества международного сообщества для их решения. Статус «неарктической страны» подчёркивал место Китая как «аутсайдера» в Арктике, и это не способствовало участию Китая в арктических делах.

\section{«Приарктический» принцип как китайский вариант «идентичности сопротивления» и «проективной» идентичности в Арктике}

Не имея доступа к принятию решений и прямых инструментов воздействия на арктическую повестку, Китай пытался реализовать свои арктические интересы путём «проталкивания» (push-in): активного лоббирования своих интересов и прав в Аркти- 
ческом совете, выгодных договорённостей в рамках двухсторонних отношений, а также конструирования и репрезентации арктической идентичности, основанной на продвижении понятия «приарктических» (или «околоарктических») государств (NearArctic State) [5, с. 119]. Предложение «приарктического» принципа - китайская инновация, выдвинутая в 2010 г. По сравнению с «циркумполярным (секторальным) принципом», бенефициарами которого являются преимущественно Россия и Канада, КНР выдвинула «приарктический принцип», который можно применить ко всем циркумполярным (арктическим) странам и приарктическим странам для управления Арктикой. В своей монографии «Геополитика Арктики и реакция Китая» китайский ученый Лу Цзюньюань предложил, чтобы термин «приарктическая страна» относился к категории стран, близких к Арктике. Критерии определения «близости» стран к Арктике, в основном, включали: 1) географическое положение: расстояние до Полярного круга не должно быть слишком большим; 2) условия движения: у страны должен быть близкий и удобный морской проход к Северному Ледовитому океану; 3) влияние: территория подвержена более прямому и глубокому влиянию Арктики на природную среду [9, c. 179]. Согласно вышеупомянутым трём критериям, в северном полушарии, особенно в Северо-Восточной Азии и Западной Европе, существует довольно много приарктических стран, таких как Китай, Южная Корея, Япония и другие страны Азии, а также Великобритания, Нидерланды и Германия в Европе. Это особая группа за пределами арктических стран, но тесно связанная с арктическими делами.

В 2012 г. китайский ученый Лю Сысы развил идею «приарктических стран», несколько упростив их критерии: 1) географическая принадлежность к северному полушарию; 2) тесные геополитические связи с Арктикой; 3) экономика и торговля тесно связана с арктическими водными путями [8]. В соответствии с этим критерием к «приарктическим», помимо циркумполярных стран, должны быть отнесены Китай, Япония, Южная Корея и Европейский Союз. «Приарктический принцип» был выдвинут, чтобы добиться двух основных целей: во-первых, усилить координацию и участие новых влиятельных игроков в арктических делах, повысить открытость и демократичность механизмов управления и не позволять отдельным странам монополизировать арктические дела; в то же время продемонстрировать уважение к исторически сложившимся правам арктических стран.

Предложение концепции «приарктической страны» подразумевает выстраивание определённой иерархии: стремление сблизиться с привилегированными «арктическими государствами» и дистанцироваться от «неарктических стран», не соответствующих указанным выше признакам [9, с. 338]. Оно является активной попыткой прорваться через ограничения статуса «неарктических стран» и демонстрирует пример «идентичности сопротивления», которая формируется акторами, которые находятся в ситуации их недооценки и/или стигматизации логикой господства. Можно говорить также о «проективной идентичности» [2, с. 23], так как Китай на основе до- 
ступного ему культурного материала строит новую коллективную идентичность, которая не только переопределяет его положение в Арктике, но и направлена на преобразование всей социальной структуры в сторону большего плюрализма и режима «отрытого доступа» (интернализации) в арктическом регионе.

В итоге Китаю удалось добиться довольно широкого признания своего «приарктического» статуса и международного консенсуса: хотя Китай не является арктической страной, не может предъявлять никаких территориальных претензий, он должен иметь соответствующие законные права и интересы в других сферах: арктического рыболовства в нетерриториальных водах, научных исследований и экспедиций, экологического мониторинга и пр. Хотя термин «приарктическая страна» подчёркивает географические отношения между Китаем и арктическим регионом, он также намекает на разницу между Китаем и другими отдалёнными неарктическими странами. Однако из-за отсутствия чётких параметров концепция «приарктической страны» сталкивается с трудностями при определении этих стандартов, и трудно найти показатель географической шкалы, такой же чёткий и широко признанный на международном уровне, как «полярный круг». Без чёткого стандарта трудно подтвердить, какие страны должны иметь соответствующие права $[10$, с. 50]. Концепция «приарктической страны» только обозначает, что Китай глубоко озабочен проблемами окружающей среды Арктики и другими важными арктическими проблемами, но не может обеспечить достаточную поддержку прав и интересов Китая в Арктике, к тому же она не была широко признана международным сообществом на практике.

\section{Роль концепции «заинтересованной стороны в Арктике» в расширении юридических прав и практической деятельности Китая в Арктике}

Позднее некоторые китайские эксперты утверждали, что статус «приарктического государства», так же, как и «неарктического государства», не может удовлетворить потребности Китая в реализации национальных интересов в Арктике, а более адекватным и рациональным является восприятие Китая в качестве одного из стейкхолдеров, «заинтересованных сторон в Арктике» (Arctic Stakeholder) [12, c. $85 ; 11$, с. $51 ; 7$, с. 38]. Термин «арктические заинтересованные стороны» позволяет избежать тех проблем, которые связаны с использованием статуса «неарктических прибрежных стран» (Non-Arctic Coastal State - термин, использованный Японией для обоснования своих прав в Арктике) и «приарктических стран» и имеет более чёткую юридическую определённость. Он даёт юридическое основание и прямо показывает, что Китай имеет право участвовать в арктических делах. Что ещё более важно, в качестве коллективной идентичности «заинтересованные стороны в Арктике» не только выходят за границы между «арктическими» и «неарктическими» странами, но также выходят за рамки границ между государственными и негосударственными субъектами [6, с. 70]. 
Как концепция, широко используемая в современной политике, экономике и праве, «заинтересованная сторона» изначально возникла как концепция корпоративного управления. С развитием экономики после войны рыночная среда, с которой столкнулись западные компании, претерпела огромные изменения. Успешная стратегия корпоративного управления должна учитывать интересы акционеров, клиентов, потребителей, сотрудников и правительства. Все эти физические или юридические лица, которые могут влиять на корпоративную деятельность или быть затронутыми ею, относятся к заинтересованным сторонам предприятия и могут отстаивать свои права в гражданских и международных судах.

С углублением глобальной взаимозависимости и постоянным возникновением общих проблем концепция «заинтересованной стороны» постепенно расширилась до глобального управления и быстро получила всеобщее признание, обеспечив теоретическую основу для множественного участия, потому что в сегодняшнюю эпоху глобализации стране трудно в одиночку эффективно решать общие проблемы, с которыми она сталкивается, а также стране трудно эффективно реализовывать свои собственные интересы. Только признавая и уважая разумные озабоченности всех заинтересованных сторон и сотрудничая друг с другом, можно более эффективно реагировать на общие проблемы и реализовывать свои интересы.

Концепция «Arctic Stakeholder» происходит из ключевого понятия теории глобального управления - «заинтересованная сторона», которая широко использовалась в научных исследованиях Арктики. Согласно этой концепции, страны с соответствующими интересами, независимо от того, где они расположены, имеют право участвовать в обсуждении вопросов и решений, которые могут их затронуть, с тем, чтобы учесть интересы всех сторон и достичь взаимной выгоды и беспроигрышных результатов. Включение в «заинтересованные стороны» общин коренных народов Арктики и различных международных организаций, заботящихся об Арктике, помогает достичь широкого международного консенсуса по насущным вопросам арктической повестки [10, с. 50].

\section{Правовые аспекты концепции «заинтересованной стороны в Арктике»: международное и корпоративное право}

Концепция «Arctic Stakeholder» позволяет КНР защищать свои позиции в Арктике не только в формате институтов «мягкой силы», но и в более формальных и жёстких рамках международного и корпоративного права, заключая двухсторонние договора с национальными и региональными правительствами, государственными и частными корпорациями. Между КНР и РФ заключено более 16 двухсторонних соглашений по вопросам сотрудничества в Арктике, в том числе с корпорациями «Газпром», «Новатэк» и др. Аналогичные соглашения существуют между КНР и другими арктическими странами: с Канадой, США, Норвегией и др. Корпо- 
ративное право действует, в том числе, в рамках ВТО и др. глобальных институтов. Китайцы приобрели репутацию очень жёстких и прагматичных переговорщиков, умело отстаивающих свои интересы.

\section{Основные принципы и инновации в «Белой книге» - официальной Стратегии КНР в Арктике}

Важным этапом в позиционировании китайского арктического дискурса стало принятие (Белой книги) [16]. 26 января 2018 г., в последний день конференции «Арктические рубежи - 2018» в Тромсё, Информационное бюро Госсовета КНР издало документ «Белая книга КНР по арктической политике» (далее - Белая книга), в которой впервые даётся систематическое изложение официальной позиции КНР по актуальным проблемам арктической повестки, взаимодействия Китая со странами А-8, сформулированы цели и приоритеты арктической политики КНР. В ней подтверждается приверженность китайским идеям «формирования сообщества единой судьбы человечества» (构建人类命运共同体), Арктики как «общего наследия человечества» (人类共同遗产), «сопряжения» (对接) проектов в рамках «Ледового шёлкового пути»), «уважения» (尊重) к правам других государств, а также западным концепциям устойчивого развития («sustainability») и совместного выигрыша («win-win result»).

Если Б. Андерсон называл нацию «воображаемым сообществом», то Арктика в известном смысле является «воображаемым регионом», который разные акторы пытаются «вообразить» в соответствии со своими интересами и ценностями. И Китай внёс свой вклад в новый этап «воображения Арктики» и развития коллективной арктической идентичности в сторону большего плюрализма и демократичности. Исследуя современную ситуацию в системе экологического управления Арктики на основе институционального подхода, китайский исследователь Чжан Чун выдвинул концепцию «панарктического сообщества», в рамках которого Китай утверждает свою арктическую идентичность. Им была предложена гипотеза, согласно которой миссия «панарктической системы» - эффективно направлять ограниченную рациональность «экономического человека» (в том числе национальные интересы), сдерживать его оппортунистические тенденции и способствовать гармоничному единству индивидуальных интересов и общих интересов общества [14].

\section{Заключение}

Таким образом, позиционирование Китая в Арктике включает эволюцию концепций от «неарктической страны» через понятие «приарктической страны» до идеи «заинтересованной стороны в Арктике». Именно концепция «Arctic Stakeholder» позволяет Китаю наиболее гибко отстаивать свои интересы в арктическом регионе с использованием международного и корпоративного права. «Заинтересованная сторона в Арктике» означает, что Китай - не разрушитель структуры управления Арктикой, а 
важный участник в управлении Арктикой. Участие Китая в управлении Арктикой это не вмешательство во внутренние дела арктических стран, а отражение озабоченности Китая по поводу Арктики как части глобальных проблем и его усилий по решению этих проблем. Участие Китая в управлении Арктикой основано на уважении суверенитета арктических государств, уважении неотъемлемых прав коренных народов Арктики, уважении интересов стран за пределами Арктики и общих интересов международного сообщества. Китай выступает за продвижение исследования и понимания Арктики, уважение и защиту Арктики с целью создания оптимальной системы управления Арктикой и многоуровневой структуры арктического сотрудничества, основанной на соблюдении существующих международных законов.

Китайские официальные лица постоянно декларируют, что развитие Арктики связано с общей судьбой человечества. «Мирная, безопасная и устойчивая Арктика отвечает интересам арктического региона и его жителей, а также общим интересам международного сообщества. Должно быть ясно, что Китай в Арктике является не конкурентом арктических стран, а важной заинтересованной стороной в Арктике и партнёром в области охраны окружающей среды и управления Арктикой. Китай готов делиться возможностями и решать проблемы с арктическими странами, странами за пределами арктического региона и другими заинтересованными сторонами в Арктике, а также расширять обмены, укреплять сотрудничество и достигать общих позиций в областях изменения климата, научных исследований, защиты окружающей среды, судоходства, устойчивого развития» [13].

Арктическая политика КНР включала такие механизмы позиционирования, как выработка арктического дискурса и арктической идентичности, артикуляция своих интересов как «заинтересованной стороны в Арктике»; агрегирование заинтересованных акторов в рамках концепции «приарктических стран»; лоббирование своих интересов на международных платформах - Арктическом совете и др. В развитии «Ледового шёлкового пути» был осуществлён синтез концептуализации и практических действий, это значимый этап арктической политики КНР. Независимо от содержания конкретных концепций арктического позиционирования Китая («приарктическая страна», «заинтересованная сторона в Арктике», Арктика как «общее наследие человечества», «панарктическое сообщество»), их продвижение на международных платформах выполнило полезную функцию: они позволили Китаю достичь успеха в создании позитивной коллективной идентичности, легитимации своей активности в Арктике, а также кооптации в институты управления Арктикой.

Борьбу Китая за своё место в Арктике с помощью концептуального переосмысления своего позиционирования как «приарктической» державы или «заинтересованной стороны в Арктике» можно интерпретировать в рамках политики идентичности как «идентичность сопротивления» элитным группам в Арктике - традиционным странам А-8 и «проективную идентичность» - последовательное конструиро- 
вание и продвижение собственного взгляда на регион и свои права в нём. Причём нужно отметить, что эта политика уже принесла полезные плоды не только КНР, но и другим «приарктическим» странам (государствам Азии и Евросоюза).

Таким образом, эволюция концепций арктической политики Китая показывает поиск и развитие идей, благодаря которым он мог артикулировать свои интересы и обрести легитимность в Арктике; расширить своё участие в международных арктических институтах и политической коммуникации в регионе. Как оригинальные национальные концепции, так и адаптированные из западного дискурса показывают, что Китай последовательно исходит из принципов «игры с ненулевой суммой» в Арктике, что составляет разительный контраст со сторонниками так называемой «реалполитики», которая исходит из концепции антагонистических противоречий («игры с нулевой суммой»), и права сильного, оглашаемого в современных международных документах США и других стран.

\section{Список источников}

1. Алмонд, Г. Сравнительная политология сегодня: мировой обзор / Г. Алмонд, Дж. Пауэлл. - Москва : Аспект Пресс, 2002. - 537 с.

2. Миненков, Г. Я. Политика идентичности с точки зрения современной социальной теории // Политическая наука. - 2005. - № 3. - С. 21-38.

3. Arctic Council: «Declaration on the establishment of the Arctic Council», Sept. 19, 1996. - URL: https://oaarchive.arctic-council.org/handle/11374/85 (дата обращения: 22.06.2020).

4. Castells, M. The power of identity / M. Castels. - Cambridge, Mass. : Blackwell, 1997. - XV, $461 \mathrm{p}$.

5. Wu, F. China's accent in global governance and the Arctic // Вестник СанктПетербургского университета. Серия 6, Философия. Культурология. Политология. Право. Международные отношения. - 2016. - № 2. - С. 118-126.

6. 董利民. 中国《北极利益攸关者》身份建构一理论与实践 // 太平洋学报. - Дон, Лимин. Построение идентичности Китая «арктическая заинтересованная сторона»: теория и практика // Тихоокеанский вестник. - 2017. - № 6. - С. 65-77.

7. 李振福. 中国的北极观理论体系构建. 亚太安全与海洋研究. - Ли, Чжэньфу. Построение китайской системы теории об Арктике // Исследование безопасности в Азиатско-Тихоокеанском регионе и океане. - 2020. - № 06. - С. 33-52.

8. 柳思思. 《近北极机制》的提出与中国参与北极 // 社会科学. - Лю, Сысы. Предложение «Приарктического механизма» и участие Китая в Арктике // Социальные науки. - 2012. - № 10. - С. 26-34.

9. 陆俊元. 北极地缘政治与中国应对 / 陆俊元. - 北京: 时事出版社, 2010. 297頁. - Лу, Цзюньюань. Геополитика Арктики и ответ Китая / Цзюньюань Лу. Пекин : Пресса о текущих событиях, 2010. - 297 с. 
10. 阮建平.《近北极国家》还是《北极利益做关者》一中国参与北极的身份思考 / 国际论坛. - Жуань, Цзяньпин. «Приарктическая страна» или «заинтересованная сторона в Арктике» - соображения по поводу участия Китая в Арктике // Международный форум. - 2016. - № 1. - С. 47-52, 80-81.

11. 孙凯.参与实践、话语互动与身份承认一一理解中国参与北极事务的进程 // 世界经济与政治. - Сунь, Кай. Участие в практике, дискурсивное взаимодействие и идентичности: понимание процесса участия Китая в арктических делах // Мировая экономика и политика. - 2014. - № 7. - С. 42-62, 157.

12. 王新和.国家利益视角下的中国北极身份 // 太平洋学报. - Ван, Синьхэ. Арктическая идентичность Китая с точки зрения национальных интересов // Тихоокеанский вестник. - 2013. - № 5. - С. 81-89.

13. 王毅部长在第三届北极圈论坛大会开幕式上的致辞. - Выступление Министра иностранных дел Ван И на открытии III международной конференции «Северный полярный круг». - URL: http://www.gov.cn/guowuyuan/vom/201510/19/content_2950053.htm (дата обращения: 22.06.2020).

14. 张冲. 中国参与北极环境治理 // 武汉大学(论文). - Чжан, Чун. Участие Китая в управлении окружающей средой в Арктике / Чун Чжан ; Уханьский университет : дис. ... д-ра управленческих наук. - Ухань, 2017.

15. 赵宁宁. 冰岛与北极治理: 战略考量及政策实践 / 赵宁宁,欧开飞 // 欧洲研究. Чжао, Ниннин. Исландия и управление в Арктике: стратегические соображения и политическая практика / Ниннин Чжао, Кайфэй Оу // Исследования по Европе. - 2015. № 4. - C. 114-125.

16. 中华人民共和国国务院新闻办公室. 中国的北极政策. 人民出版社. - Информационное бюро Госсовета КНР. Арктическая политика Китая. - Пекин : Народное издательство, 2018, 26 января. - 22 с.

\section{Информация об авторе}

Лэй Шуан - старший преводаватель Хайнаньского университета (КНР), преподаватель-исследователь Дальневосточного федерального университета (Россия).

\section{References}

1. Almond G., Powell J. Sravnitel'naya politologiya segodnya: mirovoi obzor [Comparative political science today: world survey]. Moscow: Aspect Press Publ., 2002. 537 p.

2. Minenkov G. Ya. Politika identichnosti s tochki zreniya sovremennoi sotsial'noi teorii [Identity politics from the point of view of modern social theory]. Politicheskaya nauka, 2005, no. 3, pp. 21-38. 
3. Arctic Council: "Declaration on the establishment of the Arctic Council", Sept. 19, 1996. Available at: https://oaarchive.arctic-council.org/handle/11374/85 (accessed 22.06.2020).

4. Castells M. The power of identity. Cambridge, Mass.: Blackwell, 1997. XV, 461 p.

5. Wu F. China's accent in global governance and the Arctic. Vestnik SanktPeterburgskogo universiteta. Seriya 6, Filosofiya. Kul'turologiya. Politologiya. Pravo. Mezhdunarodnye otnosheniya, 2016, no. 2, pp. 118-126.

6. Don Limin. Building China's identity "Arctic Stakeholder": theory and practice. Pacific Bulletin, 2017, no. 6, pp. 65-77. (In Chinese).

7. Li Zhenfu. Building a Chinese system of theory about the Arctic. Research of security in the Asia-Pacific region and the ocean, 2020, no. 06, pp. 33-52. (In Chinese).

8. Liu Sissy. Proposal of the "Subarctic Mechanism" and China's participation in the Arctic. Social Sciences, 2012, no. 10, pp. 26-34. (In Chinese).

9. Lu Junyuan. Arctic geopolitics and China's response. Moscow: Press about current events, 2010. 297 p. (In Chinese).

10. Ruan Jianping. "Subarctic country" or "interested party in the Arctic" - considerations about China's participation in the Arctic. International Forum, 2016, no. 1, pp. 47-52, 80-81. (In Chinese).

11. Sun Kai. Participation in practice, discursive interaction and identities: understanding the process of China's participation in Arctic affairs. World Economy and Politics, 2014, no. 7, pp. 42-62, 157. (In Chinese).

12. Wang Xinhe. Arctic identity of China from the point of view of national interests. Pacific Bulletin, 2013, no. 5, 81-89. (In Chinese).

13. Speech by Minister of Foreign Affairs Wang Yi at the opening of the III International Conference "Arctic Circle". Available at: http://www.gov.cn/guowuyuan/ vom/2015-10/19/content_2950053.htm (accessed 22 June 2020). (In Chinese).

14. Zhang Chun. China's participation in environmental management in the Arctic. Wuhan University. Dis. Dr. of Management . Wuhan, 2017. (In Chinese).

15. Zhao Ninning, Ou Kaifei. Iceland and Arctic governance: strategic considerations and political practice. European Studies, 2015, no. 4, pp. 114-125. (In Chinese).

16. Information Bureau of the State Council of the People's Republic of China. Arctic policy of China. Beijing: People's Publishing House, 2018, January 26. 22 p. (In Chinese).

\section{Information about the author}

Lei Shuang - Lecturer, Hainan University (China); Academic Researcher of Far Eastern Federal University (Russia). 